\title{
Blood Pressure and Global Risk Assessment in a Swedish Population
}

\author{
Jenny Eckner, ${ }^{1}$ Charlotte A. Larsson, ${ }^{2}$ Lennart Råstam, ${ }^{2}$ and Ulf Lindblad ${ }^{1}$ \\ ${ }^{1}$ Department of Primary Health Care, Institute of Medicine, Sahlgrenska Academy, University of Gothenburg, \\ Arvid Wallgrens Backe 4, Hus 7, P.O. Box 454, 40530 Gothenburg, Sweden \\ ${ }^{2}$ Department of Clinical Sciences/Community Medicine, Lund University, Clinical Research Centre, SUS Malmö, \\ 20502 Malmö, Sweden \\ Correspondence should be addressed to Ulf Lindblad, ulf.lindblad@gu.se
}

Received 5 June 2012; Revised 27 July 2012; Accepted 27 July 2012

Academic Editor: Claudio Borghi

Copyright ( $\odot 2012$ Jenny Eckner et al. This is an open access article distributed under the Creative Commons Attribution License, which permits unrestricted use, distribution, and reproduction in any medium, provided the original work is properly cited.

This study investigated the association between SCORE and the 2007 ESH-ESC blood pressure categories and explored achievements of blood pressure goals considering global risk. In 2001-2005, a random sample of inhabitants aged 30-74 years in southwestern Sweden was invited to a survey of cardiovascular risk factors. The study enrolled 2816 participants (participation rate $76 \%$ ). Blood pressure was categorized according to the 2007 ESH-ESC guidelines. Global risk of 10-year CVD death was estimated using the Swedish SCORE chart also accounting for additional risk from diabetes (SCORE-DM). SCORE-DM increased in both sexes from optimal blood pressure to manifest hypertension but did not differ between the normal blood pressure categories. However, SCORE-DM became significantly higher among those with temporarily high blood pressure (men 3.3 SD (1.7), women $1.1(1.8)$ ) and hypertension (3.6 (2.0), 2.0 (2.0)), compared to optimal blood pressure (1.6 (2.9), 0.6 (1.9)). In the presence of both hypertension and diabetes, high-risk subjects dominated (men 76\%, women 61\%), and correspondingly a major proportion of patients with known hypertension were at high risk at a blood pressure $\geq 160 / 100 \mathrm{~mm} \mathrm{Hg}$. These findings have strong implications on blood pressure evaluation in clinical practice and support the use of SCORE to evaluate global risk.

\section{Introduction}

Population studies in Sweden and many other countries show that hypertension is a common condition [1], which seriously affects future health and quality of life [1]. It is also evident that other diseases and cardiovascular risk factors interact with high blood pressure in determining the individual global risk [2]. Those with both hypertension and diabetes have been identified to be at a special high risk of complications $[3,4]$. To help in correctly selecting the individuals in the highest need of treatment, special risk grading tools have been developed considering other cardiovascular risk factors to calculate a global risk score (SCORE) [2, 5], and also accounting for the risk added by diabetes [6]. When the 10 -year mortality risk is at least $5 \%$, pharmacological treatment is recommended [2].

Recent studies in Skaraborg, Sweden, show a prevalence of manifest hypertension at $20 \%$ among both men and women aged 30-75 [7]. Again only one half of those with manifest hypertension fulfilled recommended treatment goals [7]. However, neither the Skaraborg Study, nor other population based studies accounted for the global risk when evaluating blood pressure control in hypertension $[8,9]$.

The aim was to study the association between SCORE and blood pressure levels according to current European expert guidelines in this Swedish population [6]. In a second step, we explored achievements of blood pressure goals considering treatment recommended by high SCORE or not.

\section{Methods}

\subsection{The Skaraborg Project}

2.1.1. Study Population. The Vara-Skövde Cohort (VSC) was collected 2001-2005 as a random sample of subjects aged 30-74 years residing in these two small municipalities in southwestern Sweden. Of a total 2816 subjects 1400 were men 
and 1416 women and the participation rate $76 \%$ as described in detail before [10].

\subsection{Procedures}

2.2.1. Measurements. The participants provided detailed information on medical history and ongoing medication and filled in a validated questionnaire regarding life styles. A standard blood pressure (right A. Brachialis) to the nearest $2 \mathrm{~mm} \mathrm{Hg}$ was measured twice in a supine position, with one minute in between. The arm was placed in heart level by the support of a special pillow, and the cuff was automatically adjusted to the circumferences of the upper arm using a special device [11]. The mean of the two blood pressure readings was used for categorisation and for analyses. Body height (nearest $\mathrm{cm}$ ) and body weight (nearest $0.1 \mathrm{~kg}$ ) were measured in light clothing and without shoes with a calibrated scale. Waist circumference was measured to the closest $\mathrm{cm}$ between the lowest rib margin and iliac crest and hip circumference correspondingly at the largest circumference between waist and thighs. Body mass index (BMI $\mathrm{kg} \mathrm{m}^{-2}$ ) was calculated as body weight $(\mathrm{kg})$ divided by body height ${ }^{2}\left(\mathrm{~m}^{2}\right)$. Fasting venous blood samples were drawn in the morning after an overnight $10 \mathrm{~h}$ fast, and a standard oral glucose tolerance test (OGTT) was conducted according to WHO [12].

2.2.2. Blood Pressure Categories. Untreated subjects with a blood pressure of at least at $140 / 90 \mathrm{~mm} \mathrm{Hg}$ were seen again at a second visit within 2 weeks, and if still $\geq 140$ and/or $90 \mathrm{~mm} \mathrm{Hg}$, they were seen a third time again within 2 weeks. Those with a high blood pressure at the first study visit who had a normal blood pressure $(<140 /<90 \mathrm{~mm} \mathrm{Hg}$, both systolic and diastolic) at the second or third visit were considered normotensive. However, for this paper, they were considered to have an unstable blood pressure. Normal blood pressure was defined in accordance with the 2007 ESH-ESC Guidelines [6] and further divided into three categories: normal optimal $(\leq 120 / 80 \mathrm{~mm} \mathrm{Hg})$, normal $(\leq 130 / 85 \mathrm{~mm} \mathrm{Hg})$, and normal high $(<140 / 90 \mathrm{~mm} \mathrm{Hg})$. If SBP and DBP belonged to different categories, the highest was chosen.

2.3. Definitions. A diagnosis of hypertension was considered when three consecutive high readings with two-week intervals ( $\geq 140$ systolic and/or $\geq 90 \mathrm{~mm}$ Hg diastolic) were registered [3], or when a known diagnosis set by a physician was documented. Manifest hypertension was further categorised as grade 1 (140-159 $\mathrm{mm} \mathrm{Hg}$ systolic and/or 90-99 diastolic), grade 2 (160-179 systolic and/or 100-109 diastolic), or grade 3 hypertension ( $\geq 180$ systolic and/or $\geq 110$ diastolic) in accordance with current European guidelines. International guidelines have been used for the diagnosis of type 2 diabetes [13].

2.4. Risk Score Algorithm. The score chart of Sweden was used to estimate the 10-year risk of cardiovascular death, accounting for risks based on sex, age, systolic blood pressure, total serum cholesterol, and on current smoking $[2,5]$. Based on individual values in these variables, all participants were placed in the corresponding score cell thus to be assigned a risk estimation according to SCORE. The corresponding risk accounting for the risk added by the presence of diabetes was calculated by the multiplication by 2 in men and by 4 in women $[5,6]$. As suggested in SCORE $[2,5]$, the global risk was considered as high if the 10-year risk of cardiovascular death $\geq 5$ percent (SCORE-HIGH), and correspondingly low if $<5$ percent. For SCORE-DM, score with diabetes included, the same procedure was done, and considered high if the 10-year risk of cardiovascular death $\geq 5$ percent (SCORE-DM-HIGH). 10 percent of the participants were randomly chosen to have their score manually calculated from the chart. The 10-year mortality risk was accordingly considered high or low and was in all cases found to be the same as when based on the algorithm in all participants.

2.5. Statistical Analysis. SPSS Base System for Windows 19.0 was used for data analyses. All proportions of the study population were age-standardized by five-year age groups using the whole Skövde-Vara population 30-75 years as standard, while means were adjusted for differences in age using general linear model (GLM). GLM was used to compare means between groups in continuous variables, and results were given as differences with $95 \%$ confidence intervals (95\% CI). Logistic regression was used to estimate associations between categorical variables, and results were presented as odds ratio (OR) with 95\% confidence intervals (CI). Confounding was accounted for by multivariate analyses and by stratification. All tests were 2 sided, and statistical significance was assumed if $P<0.05$.

\section{Results}

The distribution of blood pressure categories according to the 2007 European guidelines is shown in Figure 1. The overall proportion of normal blood pressure was $74 \%$, of unstable blood pressure $6 \%$, and of hypertension $20 \%$ in both men and women. The normal optimal blood pressure was the most common category in both men and women. Table 1 shows that $13 \%$ of the men and $1 \%$ of the women were categorized as high risk (10-year risk of cardiovascular death $\geq 5 \%$ ), when also diabetes was considered the corresponding proportions were $14 \%$ and $4 \%$, respectively.

Table 2 shows the study characteristics by blood pressure categories. The mean risk scores did not differ between the normal blood pressure categories. However, in both sexes, SCORE became significantly higher among those with unstable blood pressure and manifest hypertension, respectively, than in those with optimal blood pressure. The proportion of subjects defined as high risk increased from normal blood pressure (2\%) to hypertension $(46 \%)$ in men, and correspondingly from $0 \%$ to $7 \%$ in women. When diabetes risk was accounted for, the proportions increased from $3 \%$ to $50 \%$ in men and from $0 \%$ to $19 \%$ in women. In subjects with known hypertension, these proportions 


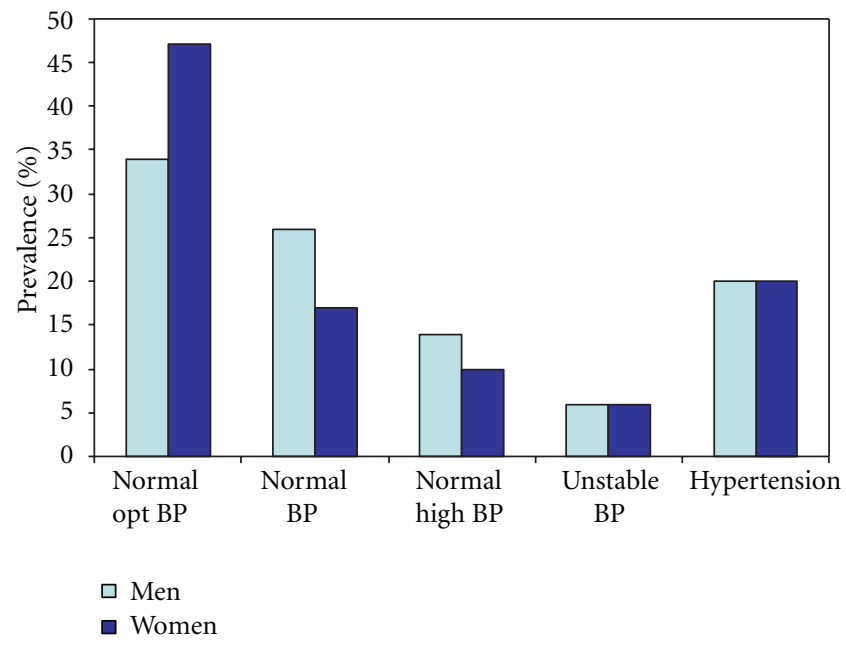

FIgURE 1: The figure illustrates the distribution (\%) of blood pressure (BP) categories according to the 2007 ESH-ESC guidelines in men and women, respectively. The 2007 ESH-ESC blood pressure categories; normal optimal $\mathrm{BP}<120 / 80 \mathrm{~mm} \mathrm{Hg}$, normal BP $<130 / 85$ mm Hg, normal high BP $<140 / 90$ mm Hg. Hypertension was defined as known documented diagnosis for high blood pressure, or by three consecutive BP reading $\geq 140 / 90 \mathrm{~mm} \mathrm{Hg}$ (systolic and/or diastolic). When the BP exceeded these limits only once or twice, the BP was categorised as unstable.

TABLE 1: Study characteristics of men and women participating in the Vara-Skövde population survey 2001-2005.

\begin{tabular}{lcccc}
\hline & \multicolumn{2}{c}{ Men } & \multicolumn{2}{c}{ Women } \\
& $n=1400$ & \multicolumn{2}{c}{$n=1416$} \\
& $m$ & $(\mathrm{SD})$ & $m$ & $(\mathrm{SD})$ \\
\hline Age (years) & 47.8 & $(11.8)$ & 47.8 & $(11.7)$ \\
Systolic blood pressure (mm Hg) & 124 & $(14.2)$ & 119 & $(14.2)$ \\
Diastolic blood pressure (mm Hg) & 72 & $(9.5)$ & 69 & $(9.6)$ \\
Serum cholesterol (mmol L $\left.^{-1}\right)$ & 5.3 & $(1.0)$ & 5.2 & $(1.0)$ \\
SCORE $^{\mathrm{a}}$ & 1.6 & $(1.6)$ & 0.5 & $(1.6)$ \\
SCORE-DM $^{\mathrm{b}}$ & 1.9 & $(2.5)$ & 0.8 & $(2.5)$ \\
\hline & $n$ & $(\%)$ & $n$ & $(\%)$ \\
\hline Daily smoking & 216 & $(15)$ & 289 & $(20)$ \\
Known diabetes $^{\mathrm{c}}$ & 51 & $(5)$ & 42 & $(4)$ \\
SCORE-HIGH $^{\mathrm{d}}$ & 179 & $(13)$ & 19 & $(1)$ \\
SCORE-DM-HIGH $^{\mathrm{e}}$ & 200 & $(14)$ & 52 & $(4)$ \\
\hline
\end{tabular}

a SCORE: risk score according to the original model, with missing values for 6 men and 4 women.

bSCORE-DM: risk score considering diabetes, with missing values for 7 men and 6 women.

${ }^{\mathrm{c} S e l f}$-reported doctors diagnosis of diabetes (type 1 or type 2).

dSCORE-HIGH: 10 -year risk of cardiovascular death $\geq 5$ percent, with missing values for 6 men and 4 women.

eSCORE-DM-HIGH: 10-year risk of cardiovascular death $\geq 5$ percent considering diabetes, with missing values for 5 men and 3 women.

were considerably higher when treatment goals were not met; $60 \%$ in men and $43 \%$ in women when blood pressure was $\geq 160 / 100 \mathrm{~mm} \mathrm{Hg}$ (grade 2 hypertension), and 57\%

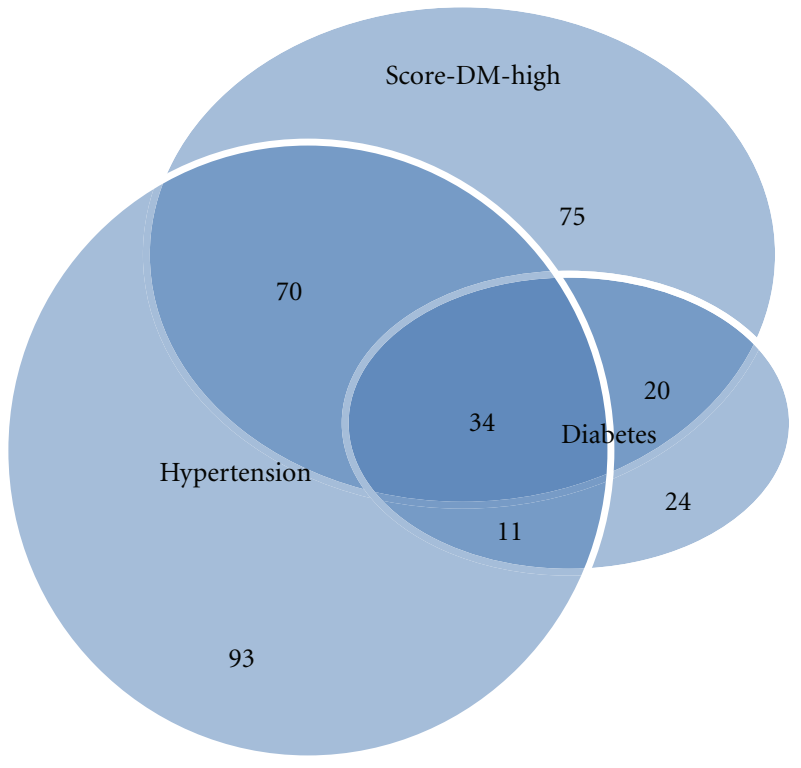

(a) Men

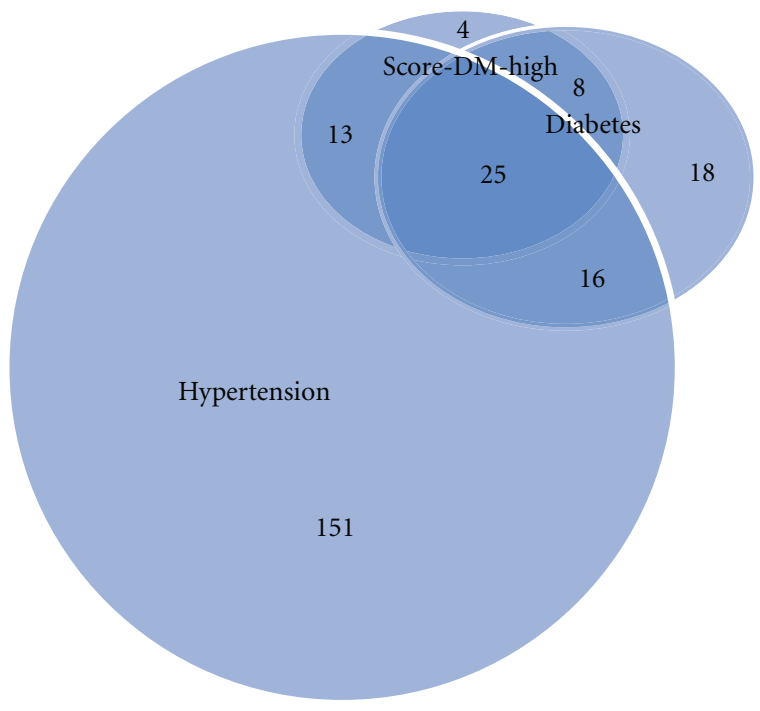

(b) Women

Figure 2: Venn diagrams in men (a) and women (b), showing the overlap between categories of hypertension, diabetes, and high risk score, respectively, accounting for diabetes.

and $100 \%$, respectively, when $\geq 180 / 110 \mathrm{~mm} \mathrm{Hg}$ (grade 3 hypertension).

Characteristics of high and low risk subjects, based on SCORE-DM-HIGH, are shown in Figure 2. In the presence of both hypertension and diabetes, high-risk subjects dominate, $76 \%$ in men and $61 \%$ in women. Table 3 shows accordingly levels of risk factor variables included in SCOREDM stratified by SCORE-DM being high or not. In low risk subjects, even in the presence of both diabetes and hypertension, age and concentrations of lipids were low. Men and women with high score without any diagnosis of hypertension or diabetes were older and had higher 
TABLE 2: Comparison of common cardiovascular disease risk factors between categories of hypertension in men and women using aware controlled hypertension as reference. The Vara-Skövde Cohort 2001-2005 within the Skaraborg Project.

\begin{tabular}{|c|c|c|c|c|c|}
\hline \multirow[b]{2}{*}{ Men } & \multicolumn{3}{|c|}{ Normal blood pressure } & \multirow{2}{*}{$\begin{array}{c}\text { Unstable blood pressure } \\
(n=70)\end{array}$} & \multirow{2}{*}{$\begin{array}{c}\text { Hypertension } \\
(n=209)\end{array}$} \\
\hline & Optimal $(n=557)$ & Normal $(n=385)$ & High $(n=179)$ & & \\
\hline \multicolumn{6}{|l|}{ Age } \\
\hline Mean (SD) & \multirow{2}{*}{$42.8(8.5)$} & $45.0(10.0)$ & $51.9(12.3)$ & $55.4(11.1)$ & $60.5(10.5)$ \\
\hline $\operatorname{Diff}(\mathrm{CI})$ & & $2.2(1.0 ; 3.5)$ & $9.2(7.5 ; 10.9)$ & $12.7(10.2 ; 15.1)$ & $17.7(16.1 ; 19.3)$ \\
\hline \multicolumn{6}{|c|}{ Systolic BP (mm Hg) } \\
\hline Mean (SD) & \multirow{2}{*}{$110.9(8.9)$} & $123.4(8.5)$ & $132.9(8.5)$ & $144.2(8.6)$ & $144.9(9.4)$ \\
\hline $\operatorname{Diff}(\mathrm{CI})$ & & $12.5(11.4 ; 13.6)$ & $22.0(20.5 ; 23.4)$ & $33.2(31.1 ; 35.4)$ & $34.0(32.4 ; 35.5)$ \\
\hline \multicolumn{6}{|c|}{ Diastolic BP (mm Hg) } \\
\hline Mean (SD) & \multirow{2}{*}{$66.0(8.3)$} & $71.4(8.0)$ & $76.9(8.0)$ & $83.7(8.0)$ & $81.8(8.8)$ \\
\hline Diff $(\mathrm{CI})$ & & $5.8(4.8 ; 6.9)$ & $11.4(10.0 ; 12.8)$ & $18.2(16.1 ; 20.2)$ & $16.3(14.8 ; 17.8)$ \\
\hline \multicolumn{6}{|c|}{ Total chol (mmol/L) } \\
\hline Mean (SD) & \multirow{2}{*}{$5.3(1.1)$} & $5.4(1.0)$ & $5.4(1.0)$ & $5.7(1.0)$ & $5.2(1.1)$ \\
\hline $\operatorname{Diff}(\mathrm{CI})$ & & $0.1(-0.1 ; 0.2)$ & $-0.2(0.0 ; 0.3)$ & $0.4(0.1 ; 0.6)$ & $-0.1(-0.3 ; 0.1)$ \\
\hline \multicolumn{6}{|l|}{ SCORE } \\
\hline Mean (SD) & \multirow{2}{*}{$1.4(1.9)$} & $1.2(1.9)$ & $1.2(1.9)$ & $2.8(1.9)$ & $2.7(2.1)$ \\
\hline Diff $(\mathrm{CI})$ & & $-0.1(-0.3 ; 0.1)$ & $-0.1(-0.4 ; 0.2)$ & $1.5(1.0 ; 2.0)$ & $1.4(1.0 ; 1.7)$ \\
\hline \multicolumn{6}{|l|}{ SCORE-DM } \\
\hline Mean (SD) & \multirow{2}{*}{$1.6(2.9)$} & $1.4(2.8)$ & $1.2(2.8)$ & $3.3(1.7)$ & $3.6(2.0)$ \\
\hline $\operatorname{Diff}(\mathrm{CI})$ & & $-0.2(-0.5 ; 0.2)$ & $-0.3(-0.8 ; 0.2)$ & $1.7(1.0 ; 2.4)$ & $2.0(1.5 ; 2.6)$ \\
\hline \multicolumn{6}{|l|}{ Smoking } \\
\hline$n(\%)$ & \multirow{2}{*}{$87(16)$} & $59(14)$ & $30(17)$ & $15(22)$ & $25(12)$ \\
\hline $\mathrm{OR}(\mathrm{CI})$ & & $1.0(0.7 ; 1.4)$ & $1.1(0.7 ; 1.7)$ & $1.5(0.8 ; 2.9)$ & $0.7(0.4 ; 1.3)$ \\
\hline \multicolumn{6}{|l|}{ Diabetes } \\
\hline$n(\%)$ & \multirow{2}{*}{$15(3)$} & $12(3)$ & $10(6)$ & $7(10)$ & $45(22)$ \\
\hline OR (CI) & & $1.0(0.5 ; 2.2)$ & $1.2(0.5 ; 2.9)$ & $2.0(0.7 ; 5.3)$ & $3.9(1.9 ; 8.0)$ \\
\hline \multicolumn{6}{|l|}{ CVD } \\
\hline$n(\%)$ & \multirow{2}{*}{$7(1)$} & $5(1)$ & $11(6)$ & $1(1)$ & $36(17)$ \\
\hline $\mathrm{OR}(\mathrm{CI})$ & & $0.7(0.2 ; 2.2)$ & $1.4(0.5 ; 4.1)$ & $0.2(0.0 ; 2.1)$ & $2.6(1.0 ; 6.5)$ \\
\hline SCORE-HIGH & & & & & \\
\hline$n(\%)$ & & $19(5)$ & $28(16)$ & $25(37)$ & $95(46)$ \\
\hline $\mathrm{OR}(\mathrm{CI})$ & $12(2)$ & $1.3(0.5 ; 3.9)$ & $1.3(0.5 ; 3.7)$ & $10.2(3.2 ; 33.2)$ & $4.9(1.9 ; 12.2)$ \\
\hline SCORE-HIGH & & & & & \\
\hline$n(\%)$ & $15(3)$ & $20(5)$ & $33(18)$ & $28(41)$ & $104(50)$ \\
\hline $\mathrm{OR}(\mathrm{CI})$ & $10(0)$ & $1.0(0.3 ; 2.6)$ & $1.3(0.5 ; 3.5)$ & $10.1(3.3 ; 30.5)$ & $4.7(2.0 ; 11.2)$ \\
\hline Women & Optimal $(n=805)$ & Normal $(n=230)$ & High $(n=115)$ & $(n=60)$ & $(n=206)$ \\
\hline Age & & & & & \\
\hline Mean (SD) & $42.2(7.9)$ & $48.7(10.7)$ & $55.4(11.9)$ & $58.2(9.5)$ & $61.1(10.3)$ \\
\hline $\operatorname{Diff}(\mathrm{CI})$ & $42.2(7.9)$ & $6.5(5.1 ; 7.8)$ & $13.2(11.4 ; 15.0)$ & $16.0(13.6 ; 18.4)$ & $18.9(17.5 ; 20.3)$ \\
\hline Systolic BP (mn & & & & & \\
\hline Mean (SD) & & $122.8(8.7)$ & $132.6(8.9)$ & $143.9(8.9)$ & $145.4(9.9)$ \\
\hline Diff $(\mathrm{CI})$ & $108.1(9.6)$ & $14.6(13.3 ; 15.9)$ & $24.5(22.7 ; 26.3)$ & $35.8(33.4 ; 38.2)$ & $37.2(35.6 ; 38.9)$ \\
\hline Diastolic BP (m & & & & & \\
\hline Mean (SD) & $63.1(8.6)$ & $71.9(7.8)$ & $75.0(8.0)$ & $81.1(8.0)$ & $79.3(8.9)$ \\
\hline Diff $(\mathrm{CI})$ & $63.1(8.6)$ & $8.9(7.7 ; 10.1)$ & $12.0(10.3 ; 13.6)$ & $18.0(15.8 ; 20.2)$ & $16.2(14.8 ; 17.7)$ \\
\hline Total chol (mm & & & & & \\
\hline Mean (SD) & $5.2(1.1)$ & $5.3(1.0)$ & $5.4(1.0)$ & $5.5(1.0)$ & $5.1(1.1)$ \\
\hline $\operatorname{Diff}(\mathrm{CI})$ & $5.2(1.1)$ & $0.2(0.0 ; 0.3)$ & $0.2(0.0 ; 0.4)$ & $0.3(0.0 ; 0.6)$ & $0.0(-0.2 ; 0.1)$ \\
\hline
\end{tabular}


TABle 2: Continued.

\begin{tabular}{|c|c|c|c|c|c|}
\hline & \multicolumn{3}{|c|}{ Normal blood pressure } & \multirow{2}{*}{$\begin{array}{c}\text { Unstable blood pressure } \\
(n=60)\end{array}$} & \multirow{2}{*}{$\begin{array}{c}\text { Hypertension } \\
(n=206)\end{array}$} \\
\hline Women & Optimal $(n=805)$ & Normal $(n=230)$ & $\operatorname{High}(n=115)$ & & \\
\hline \multicolumn{6}{|l|}{ SCORE } \\
\hline Mean (SD) & \multirow{2}{*}{$0.4(0.8)$} & $0.3(0.7)$ & $0.4(0.8)$ & $0.9(0.8)$ & $1.1(0.8)$ \\
\hline $\operatorname{Diff}(\mathrm{CI})$ & & $-0.1(-0.2 ; 0.0)$ & $-0.1(-0.2 ; 0.1)$ & $0.4(0.2 ; 0.6)$ & $0.6(0.5 ; 0.8)$ \\
\hline \multicolumn{6}{|l|}{ SCORE-DM } \\
\hline Mean (SD) & \multirow{2}{*}{$0.6(1.9)$} & $0.3(1.7)$ & $0.4(1.8)$ & $1.1(1.8)$ & $2.0(2.0)$ \\
\hline $\operatorname{Diff}(\mathrm{CI})$ & & $-0.3(-0.6 ; 0.0)$ & $-0.2(-0.5 ; 0.2)$ & $0.5(0.0 ; 0.9)$ & $1.3(1.0 ; 1.7)$ \\
\hline \multicolumn{6}{|l|}{ Smoking } \\
\hline$n(\%)$ & \multirow{2}{*}{$162(20)$} & $50(22)$ & $26(23)$ & $12(20)$ & $39(19)$ \\
\hline $\mathrm{OR}(\mathrm{CI})$ & & $1.2(0.8 ; 1.7)$ & $1.3(0.8 ; 2.2)$ & $1.2(0.6 ; 2.3)$ & $1.1(0.7 ; 1.8)$ \\
\hline \multicolumn{6}{|l|}{ Diabetes } \\
\hline$n(\%)$ & \multirow{2}{*}{$11(1)$} & $5(2)$ & $6(5)$ & $5(8)$ & $42(20)$ \\
\hline $\mathrm{OR}(\mathrm{CI})$ & & $1.2(0.4 ; 3.5)$ & $2.2(0.7 ; 6.5)$ & $3.3(1.0 ; 10.6)$ & $8.2(3.5 ; 19.0)$ \\
\hline \multicolumn{6}{|l|}{ CVD } \\
\hline$n(\%)$ & \multirow{2}{*}{$6(1)$} & $6(3)$ & $2(2)$ & $1(2)$ & $12(6)$ \\
\hline $\mathrm{OR}(\mathrm{CI})$ & & $1.1(0.3 ; 3.7)$ & $0.3(0.0 ; 1.5)$ & $0.3(0.0 ; 2.4)$ & $0.6(0.2 ; 2.0)$ \\
\hline \multicolumn{6}{|l|}{ SCORE-HIGH } \\
\hline$n(\%)$ & \multirow{2}{*}{$1(0)$} & $0(0)$ & $2(2)$ & $2(3)$ & $14(7)$ \\
\hline $\mathrm{OR}(\mathrm{CI})$ & & $0.0(0.0 ;-)$ & $1.4(0.4 ; 8.6)$ & $3.0(0.8 ; 16.9)$ & $3.9(1.8 ; 24.3)$ \\
\hline \multicolumn{6}{|c|}{ SCORE-HIGH-DM } \\
\hline$n(\%)$ & \multirow{2}{*}{$3(0)$} & $0(0)$ & $5(4)$ & $5(8)$ & 39 (19) \\
\hline OR (CI) & & $0.0(0.0 ;-)$ & $1.8(0.4 ; 8.6)$ & $3.6(0.8 ; 16.9)$ & $6.6(1.8 ; 24.3)$ \\
\hline
\end{tabular}

concentrations of lipids and were often smoking. Finally all analyses were repeated among subjects aged 40-65 years, and the results were consistent with those found in the whole study population ( $30-75$ years).

\section{Discussion}

Traditional CVD risk factors increased in both men and women the higher the blood pressure category. The accumulation of risk factors among subjects with manifest hypertension and unstable blood pressure was confirmed by the global risk score that significantly separated hypertension and unstable blood pressure from all the normal blood pressure categories according the 2007 European guidelines. This pattern was even more pronounced when risk score also accounted for diabetes. Most subjects with manifest hypertension had an estimated 10-year CVD mortality risk $<5 \%$ and should thus not by routine be prescribed pharmacological treatment.

Blood pressure levels that are recommended for therapy by expert guidelines are according to this study accurately decided based on SCORE. However, global risk estimation by SCORE did not identify all subjects with a diagnosis of hypertension and/or diabetes as being at a high risk. Many study subjects with hypertension, especially women, did not reach a SCORE that indicates the need of drug treatment. Instead this study showed that a substantial proportion of men having high SCORE had neither hypertension nor diabetes. The high SCORE risk was mainly attributed to old age if hypertension or diabetes were not present (Table 3 ). When both hypertension and diabetes was present, high-risk SCORE predominated, which confirms the hazard of having both.

A major strength of this study was the high participation rate, which gives the results a high trustworthiness. It is still likely that individuals with chronic diseases or health problems prior to the study would be more reluctant to participate than healthy people, as often seen in other surveys [14]. Nevertheless, this is not likely to have had a considerable impact on the observed prevalence. Another strength of the study was the accurate blood pressure measurements and the strict diagnostic procedures, thus limiting the risk of overestimating unaware hypertension due to randomly high blood pressure levels [15].

Originally SCORE did not consider risk from diabetes, but a modified algorithm has been proposed by multiplying the score value by two in men and by four in women, which we accordingly did $[5,6]$. This also gave us the opportunity to compare the different score models in relation to the blood pressure categories in the 2007 ESH-ESC guidelines [6]. However, as expected in a healthy population, they were very similar. Originally SCORE did not include risk assessments for systolic blood pressure above $180 \mathrm{~mm} \mathrm{Hg}$ or a total for serum cholesterol above $8 \mathrm{mmol} / \mathrm{L}$. At these levels, the risks are considered so high that treatment is still indicated independently of the global risk assessment [2]. In our study population, only 23 subjects $(0.8 \%)$ had 
TABLE 3: Global risk according to SCORE characterized by SCORE variables in men and women of the Vara-Skövde Cohort in the Skaraborg Project 2001-2005.

\begin{tabular}{|c|c|c|c|c|c|c|c|c|c|c|c|}
\hline & Mort $\geq 5 \%$ & $\mathrm{DM}$ & $\mathrm{HT}$ & Age & (SD) & SBP & (SD) & Chol & $(\mathrm{SD})$ & Smoke & $(\%)$ \\
\hline \multicolumn{12}{|c|}{$\operatorname{Men}(n)$} \\
\hline 1067 & - & - & - & 43.7 & $(8.5)$ & 120.0 & $(13.7)$ & 5.4 & (1.1) & 157 & (15) \\
\hline 24 & - & + & - & 44.4 & $(8.6)$ & 125.4 & $(13.8)$ & 5.1 & $(1.0)$ & 7 & (29) \\
\hline 93 & - & - & + & 53.2 & $(8.2)$ & 139.4 & (13.3) & 5.3 & $(1.0)$ & 6 & (7) \\
\hline 11 & - & + & + & 47.8 & (11.8) & 132.8 & $(13.8)$ & 4.7 & $(1.0)$ & 0 & $(0)$ \\
\hline 75 & + & - & - & 68.2 & $(4.6)$ & 118.0 & $(15.0)$ & 5.8 & (1.1) & 23 & (31) \\
\hline 20 & + & + & - & 66.7 & $(5.7)$ & 119.8 & $(14.1)$ & 5.0 & $(1.0)$ & 4 & (20) \\
\hline 70 & + & - & + & 68.3 & $(4.9)$ & 141.7 & $(14.4)$ & 5.2 & (1.1) & 11 & (16) \\
\hline 34 & + & + & + & 68.2 & $(5.8)$ & 134.1 & (14.3) & 5.1 & $(1.0)$ & 8 & (24) \\
\hline \multicolumn{12}{|c|}{ Women $(n)$} \\
\hline 1176 & - & - & - & 45.2 & $(10.1)$ & 115.9 & (12.9) & 5.2 & $(1.0)$ & 240 & (20) \\
\hline 18 & - & + & - & 47.8 & (11.7) & 121.0 & $(14.4)$ & 5.2 & $(1.0)$ & 3 & (17) \\
\hline 151 & - & - & + & 59.7 & $(10.4)$ & 136.4 & $(14.0)$ & 5.2 & (1.0) & 28 & (19) \\
\hline 16 & - & + & + & 57.1 & $(10.1)$ & 134.2 & (14.3) & 4.5 & (1.0) & 1 & (6) \\
\hline 4 & + & - & - & 66.6 & $(4.4)$ & 120.8 & (14.4) & 6.8 & (1.0) & 4 & (100) \\
\hline 8 & + & + & - & 69.0 & $(4.2)$ & 111.4 & (14.5) & 4.8 & (1.0) & 3 & (38) \\
\hline 13 & + & - & + & 68.4 & $(9.3)$ & 155.2 & $(14.2)$ & 5.4 & $(1.0)$ & 3 & (17) \\
\hline 25 & + & + & + & 68.6 & $(3.8)$ & 131.4 & (14.7) & 4.8 & (1.0) & 4 & (16) \\
\hline
\end{tabular}

systolic blood pressure $\geq 180 \mathrm{~mm} \mathrm{Hg}$, and only 34 subjects $(1.2 \%)$ had a total serum cholesterol $\geq 8 \mathrm{mmol} / \mathrm{L}$. Originally score was constructed for the age range between 40 and 65 years. As age is such a strong risk factor almost all men older than 65 years have a mortality risk of 5 percent or more regardless of their cholesterol level, blood pressure, or smoking habits. For cardiovascular risk assessment to achieve increased utilising in primary care, we decided to include all subjects in the original study population. Still, including subject $\geq 65$ years of age would rather tend to increase the proportion with a high risk that would accordingly be recommended pharmacological treatment. Thus, the small proportion with a low 10 -year mortality risk was probably not an underestimation.

We have found that a large proportion of patients with hypertension had a low risk according to SCORE. This contradicts previous reports suggesting that SCORE overestimates cardiovascular risk [16]. This in turn may partially advocate our recent findings that only one-third of all subjects with treated hypertension achieve recommended blood pressure goals [7]. We may have to accept that some subjects, especially women, are considered adequately cared for despite not having a blood pressure $\leq 140 / 90 \mathrm{~mm} \mathrm{Hg}$. However, in patients with grade 2 or grade 3 hypertension the estimated mortality risk was considerably higher emphasizing the need of more attention for these patients.

The present findings imply that cardiovascular risk estimation using SCORE is parallel with risk increase according to 2007 ESH-ESC blood pressure categories and general expert treatment guidelines. Our findings may have strong implications on blood pressure evaluation in clinical practice and emphasize the need of nonpharmacological interventions among subjects with high normal blood pressure and low risk hypertension [17-19]. These questions should be further investigated in longitudinal population-based studies.

\section{References}

[1] National Clinical Guidance Centre, Hypertension (NICE CG 127), National Institute for Health and Clinical Excellence, 2011, http://www.nice.org.uk/nicemedia/live/13561/56007/ 56007.pdf.

[2] R. M. Conroy, K. Pyörälä, A. P. Fitzgerald et al., "Estimation of ten-year risk of fatal cardiovascular disease in Europe: the SCORE project," European Heart Journal, vol. 24, no. 11, pp. 987-1003, 2003.

[3] World Health Organization and International Society of Hypertension, "Guidelines for the Management of Hypertension," Journal of Hypertension, vol. 17, pp. 151-183, 1999.

[4] P. S. Yusuf, S. Hawken, S. Ôunuu et al., "Effect of potentially modifiable risk factors associated with myocardial infarction in 52 countries (the INTERHEART study): case-control study," The Lancet, vol. 364, no. 9438, pp. 937-952, 2004.

[5] HeartSCORE, http://www.heartscore.org/.

[6] G. Mancia, G. De Backer, A. Dominiczak et al., "ESH-ESC practice guidelines for the management of arterial hypertension: ESH-ESC task force on the management of arterial hypertension," Journal of Hypertension, vol. 25, no. 9, pp. 1751-1762, 2007.

[7] U. Lindblad, J. Ek, J. Eckner, C. A. Larsson, S. Guangliang, and L. Råstam, "Prevalence, awareness, treatment and control of hypertension-rule of thirds in The Skaraborg Project," Scandinavian Journal of Primary Health Care, vol. 30, no. 2, pp. 88-94, 2011.

[8] W. B. Kannel, R. B. D’Agostino, L. Sullivan, and P. W. F. Wilson, "Concept and usefulness of cardiovascular risk profiles," American Heart Journal, vol. 148, no. 1, pp. 16-26, 2004. 
[9] I. M. Graham, "The importance of total cardiovascular risk assessment in clinical practice," European Journal of General Practice, vol. 12, no. 4, pp. 148-155, 2006.

[10] C. A. Larsson, B. Gullberg, L. Råstam, and U. Lindblad, "Salivary cortisol differs with age and sex and shows inverse associations with WHR in Swedish women: a cross-sectional study," BMC Endocrine Disorders, vol. 9, article 16, 2009.

[11] L. Rastam and G. Sjonell, "A new device for measuring blood pressure in adults," The Lancet, vol. 337, no. 8735, pp. 249-250, 1991.

[12] K. G. M. M. Alberti and P. Z. Zimmet, "Definition, diagnosis and classification of diabetes mellitus and its complications. Part 1: diagnosis and classification of diabetes mellitus. Provisional report of a WHO consultation," Diabetic Medicine, vol. 15, pp. 539-553, 1998.

[13] WHO Study Group, “Diabetes mellitus,” Tech. Rep. 727, 1985.

[14] L. Wilhelmsen, S. Ljungberg, H. Wedel, and L. Werko, "A comparison between participants and non participants in a primary preventive trial," Journal of Chronic Diseases, vol. 29, no. 5, pp. 331-339, 1976.

[15] G. Mancia, R. Sega, C. Milesi, G. Cesana, and A. Zanchetti, "Blood-pressure control in the hypertensive population," The Lancet, vol. 349, no. 9050, pp. 454-457, 1997.

[16] I. Hartz, I. Njølstad, and A. E. Eggen, "Does implementation of the European guidelines based on the SCORE model double the number of Norwegian adults who need cardiovascular drugs for primary prevention? The Tromsø study 2001," European Heart Journal, vol. 26, no. 24, pp. 2673-2680, 2005.

[17] L. J. Appel, "Lifestyle modification as a means to prevent and treat high blood pressure," Journal of the American Society of Nephrology, vol. 14, supplement 2, pp. S99-S102, 2003.

[18] F. G. Márquez-Celedonio, O. Téxon-Fernández, A. ChávezNegrete, S. Hernández-López, S. Marín-Rendón, and S. Berlín-Lascurain, "Clinical effect of lifestyle modification on cardiovascular risk in prehypertensives: PREHIPER I Study," Revista Espanola de Cardiologia, vol. 62, no. 1, pp. 86-90, 2009.

[19] K. M. Henriksson, U. Lindblad, B. Gullberg, B. Ågren, P. Nilsson-Ehle, and L. Råstam, "Development of hypertension over 6 years in a birth cohort of young middle-aged men: the Cardiovascular Risk Factor Study in southern Sweden (CRISS)," Journal of Internal Medicine, vol. 252, no. 1, pp. 2126, 2002. 


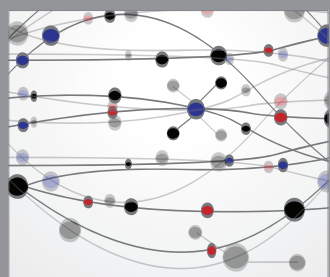

The Scientific World Journal
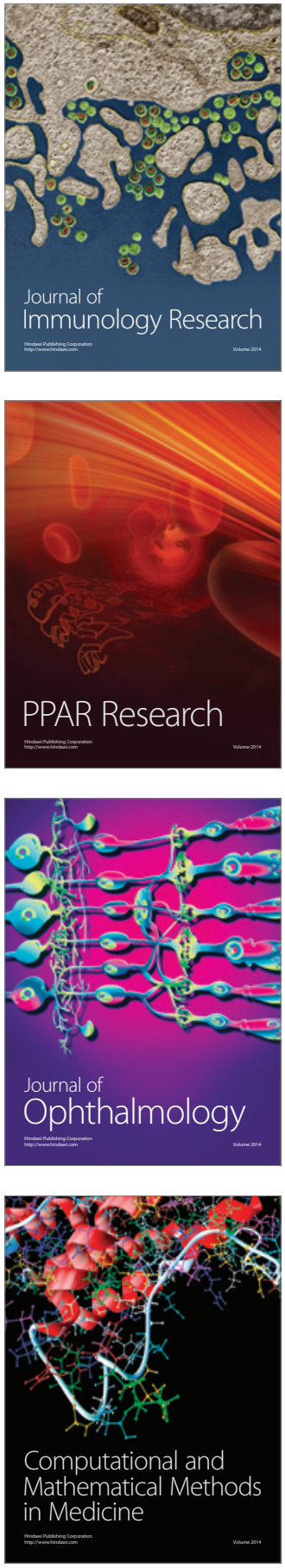

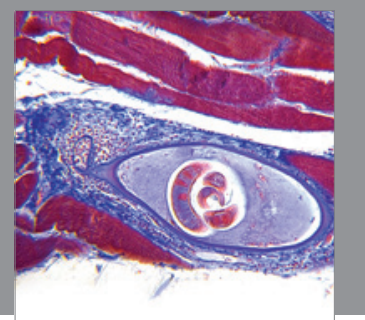

Gastroenterology

Research and Practice
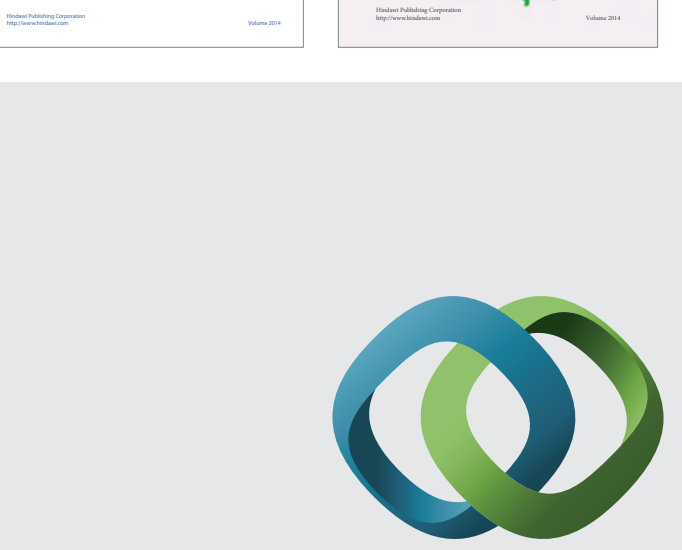

\section{Hindawi}

Submit your manuscripts at

http://www.hindawi.com
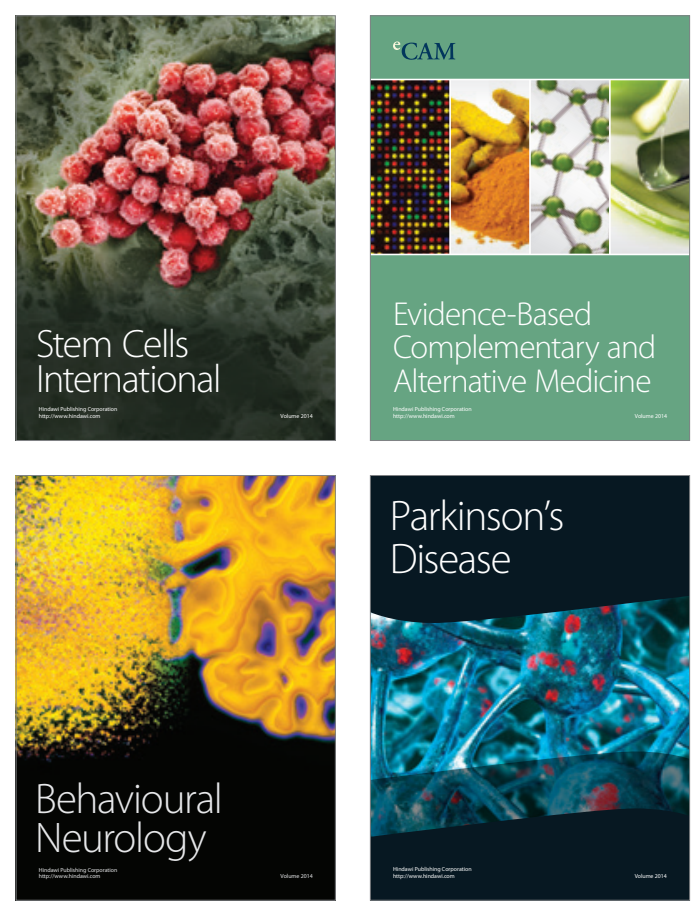

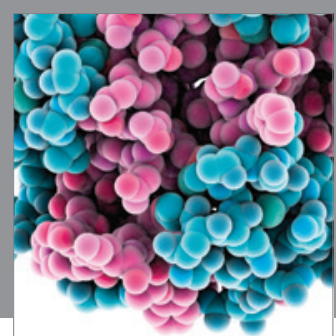

Journal of
Diabetes Research

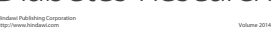

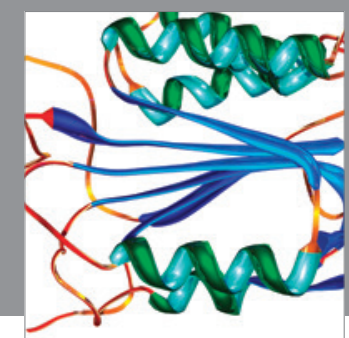

Disease Markers
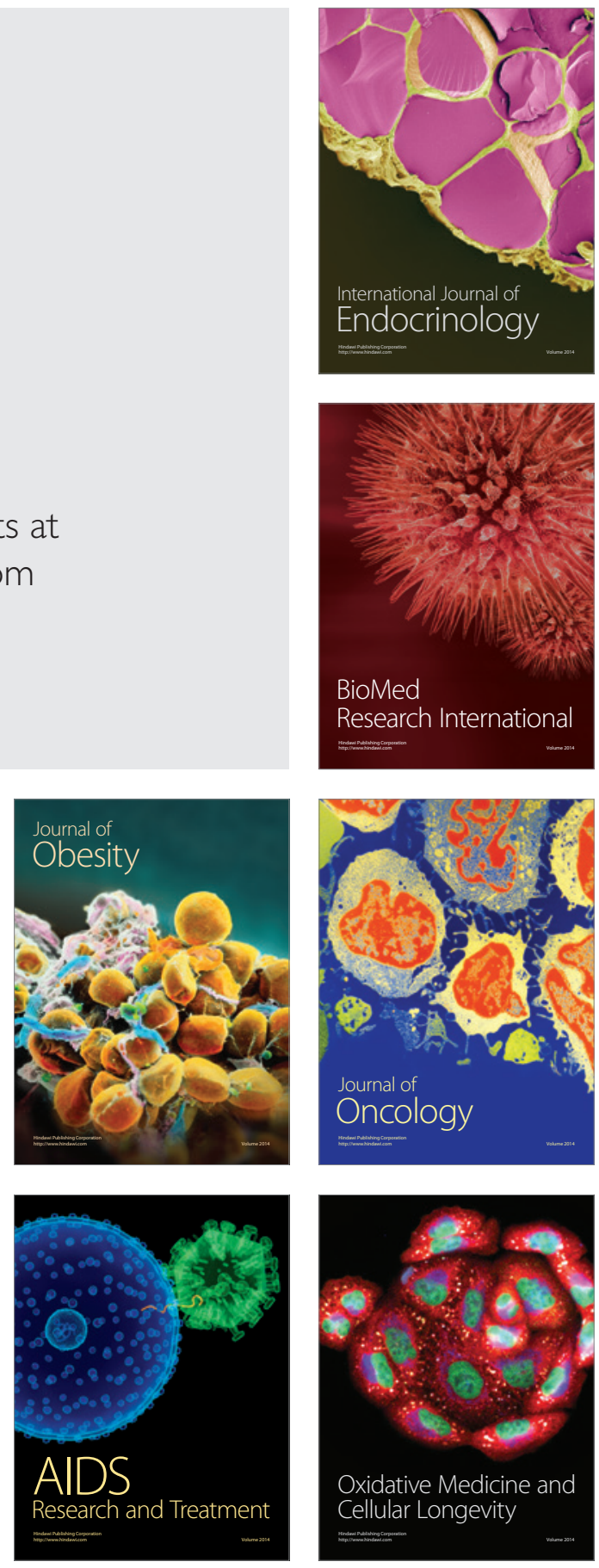